\title{
An Image of Electricity: Towards an Understanding of How People Perceive Electricity
}

\author{
Yoram Chisik \\ Madeira Interactive Technologies Institute (M-ITI) - University of Madeira \\ Campus da Penteada, 9020-105 Funchal, Portugal \\ ychisik@m-iti.org
}

\begin{abstract}
Although an enormous amount of research effort has been devoted to understanding people's energy consumption habits, visualizing their consumption and finding ways of motivating them towards more sustainable behaviours we are still in the dark with regards to people's basic perception of electricity, their concept of what electricity is and their notion of the consumption rates of various electrical devices. In this study we have employed a sketching methodology to elicit people's basic mental image of what electricity is, how they conceive of the electrical infrastructure in their home and which devices they think represent the largest drain on their wallets. Preliminary analysis of the results show that people do not have a clear mental model of electricity and tend to associate the size of the device and the duration of use with higher rates of consumption regardless of the type of device, the type of use it is put to and its actual consumption level.
\end{abstract}

\section{Introduction}

Electricity is the staple of modern life. Electrical devices from air-conditioners and light bulbs to vacuum cleaners and washing machines enable us to escape the harshness of the weather, turn night into day, and make what was once dirty clean again. Electricity powers our communication networks and fuels our production facilities, it brings to life the alarm clocks and coffee makers that wake us up in the early morning and energizes the displays that keep us busy during the day and entertained at night.

Electricity is also hidden from view as the current powering a device flows sight unseen from the generator or grid. Unless we fall victim to an incompetent electrician, or play with live wires because we have lost, or are yet to acquire our senses, most of us will never come into direct contact with live electricity, although there is always the possibility of getting struck by lightening or getting shocked by a static charge regardless of our sense or sensibility.

Thus electricity remains largely out of sight and out of mind while we regale in the use of the multitude of electrical devices that make up the fabric of the modern world. It is the invisible nature of electricity that lies at the root of some of the environmental problems currently being faced by the world's population, as behind most electrical devices lies a wall socket, and behind the wall socket lie a maze of wires and cables which more often than not lead to the belching smokestack of a power generating station. 
As we try to move towards a more sustainable future, curtailing the consumption of electricity and its associated emissions has turned out to be a particularly wicked problem. By using the term wicked problem I refer to both the standard dictionary definition of a highly serious and distressing problem and the term coined by Rittel and Webber [26] of a complex problem for which there is neither a definitive formulation nor a definitive solution.

The extent of the wickedness of the problem is revealed when one studies the literature on the subject. Not only are there issues with the sitting of power stations, the fuels and other natural resources used to power them and the complexities of managing the network of cables and wires through which the electricity flows, research into the use and consumption of energy and electricity have revealed that human nature and proclivity add a set of new dimensions to the problem.

To begin with, Pierce, Schiano and Paulos [23] have shown that people are highly resistant to change and value their convenience when using appliances, i.e. they may not forsake or delay their use of a device due to environmental considerations. While Chetty, et al [4] have observed that even persons intent on shutting down their computers during periods of inactivity stopped doing so due to the inconvenience associated with the long waits caused by the prolonged start-up and shutdown times of the computer.

To compound the problem even further consumption patterns both in terms of purchasing specific appliances and in terms of use are highly context specific, and are influenced by a host of variables ranging from personal preferences and economic ability (both past and present) to weather patterns and social norms [1], [19] and are often conducted without conscious consideration [17], [22].

HCI researchers have sought to bring the "unconscious aspects of [electricity consumption] to conscious awareness, thereby making them available for conscious choice" [27]. Pierce, Odom and Blevis [21], Froehlich, Findlater and Landay [11] and Pierce and Paulos [22] describe the various eco-visualization devices that have been constructed in order to make visible the flow of electrical energy and to highlight the amount of electricity consumed by a household. He and Greenberg [13], Mankoff, et al [16], and Foster, et al [9] describe the ways in which social networking systems and computer mediated communication have been used as means of supporting and motivating energy conservation and sustainable consumption.

However these approaches in addition to having to overcome the difficulties outlined above also have to contend with economic reality. Studies have shown that the financial incentives associated with smart-meters and eco-visualization devices are often too small to motivate behavioural change. Smart-meters and ecovisualization devices typically bring about a 5-15\% reduction on average [6], [28] and since there are no long term studies of the use of smart meters and eco-visualizations we do not know whether these savings can be sustained over time.

Dunlap [8], Bostrom, et al [2], Read, et al [25] conducted a series of studies aimed at finding what people know and understand about global warming. What they found was that although respondents showed concern over the problem their knowledge and understanding was highly limited. The respondents tended to confuse the processes involved (often having difficulty in differentiating between causes and actions) or offer highly literal interpretations. Dunlap [8] also found that these perceptions did not consistently vary across social strata and that most people were willing to admit their lack of knowledge and understanding. 
Thus much depends upon people's preferences and perceptions yet despite a tremendous amount of research work we are still in the dark with regards to how people perceive electricity. A search of the literature focused specifically on electricity and perception yielded a single reference [14] and even that dealt with people's perceptions of the aesthetic elements surrounding the placement of electrical poles and not with electricity itself.

If we are to make significant inroads into the subject of electricity consumption we first need to unsheathe the cloak of invisibility from electricity and understand how people conceive electricity and electrical consumption as opposed to examining the ways in which they use electrical devices and their perceptions of the impact of that usage on the environment which has been the primary focus of most electricity consumption studies to date. This study is our first step in building such an understanding.

\section{Research Questions}

Electricity is both a natural phenomenon and commercially available product. As a natural phenomenon electricity is most often experienced either as the physical sensation of a minor shock caused by a static electricity charge when reaching for a door knob or a railing, or as a visual sensation such as a lightning spectacle during a storm.

As a commercial product electricity is available in numerous forms of delivery and in different "strengths". Electrical utilities offer their customers a steady stream of electricity via a purpose built network for a fee. Battery manufacturers offer electricity in packaged form and generator manufacturers sell devices that produce electricity from sources as varied as gasoline and solar rays and in capacities ranging from the minute to the gargantuan.

The prevalence of commercial electricity is such that the vast majority of the world population consumes electricity in one form or another throughout the day. Those fortunate enough to live in the more developed parts of the world enjoy a constant stream of electricity in their homes and workplaces and power their mobile devices with a host of batteries. Those living in lesser-developed or remote sites use generators to either supplement or to provide the entirety of their electricity needs. Regardless of the level of development, isolation and socio-economic status one would be hard-pressed to find a location entirely devoid of some form of electricity or electrical consumption.

In all cases the electricity delivered and its quantity will be hidden from view. Unlike other forms of energy such as cow dung, wood, coal, petrol, gas or other consumables such as water, fruits or vegetables commercial electricity has no visible or felt properties. One cannot spill a bit of electricity from a cable like one would be able to do with water or petrol from a pipe, or feel whether a battery is full or empty by sensing its weight, as one would do with a water bottle or a gas canister. Electricity is an invisible resource that can neither be seen nor heard and its presence can only be inferred from the workings of the devices that are dependent on it. Indeed most of the time people only think of electricity during a power failure when the lights and the rest of the appliances on which their life depends stop working. 
As a result the mental model of electricity, i.e the perceptual image a person stores in his head and on which he bases his reasoning and decision will be based on mediated/indirect experience of using electrical devices as opposed to the direct experiences that shape our mental models of physical space and physical properties. For example we form mental models of landscapes by physically traversing the streets of a city, the aisles of a supermarket or the corridor of a friend's apartment, noting the layout of the environment, e.g. $3^{\text {rd }}$ door on the right and/or specific memorable features (landmarks) such as the fountain or the duck at the corner of the road.

\section{RQ1 - What are people's perceptions of electricity?}

Given the fact that electricity is virtually universal in both its natural and commercial forms, that practically no man alive today has known a world entirely devoid of commercial electricity and that we can only experience commercial electricity indirectly through the agency of some device it would be interesting as a starting point to find out what is the first thing that comes up in people's mind when they think of electricity.

Would people think of one of the electrical devices they use on a regular basis, would they invoke images of one of the infrastructure elements through which electricity is delivered to their homes, offices and mobiles such as electricity poles, plugs, cords and batteries, would an image of a lightning storm flash in their minds or would they think of something else entirely.

\section{RQ2 - How do people conceptualize the electrical infrastructure within their homes?}

As noted above people's relationship with electricity is an indirect one. The power of electricity is utilized through the use of electrical devices and the absence of electricity is often only felt when these devices cease to work

The average home contains a complex array of wiring, access points and devices within and between its walls. Some of the wiring is hidden from view, encapsulated into the walls, while other is visible and in plain sight. A few devices such as the refrigerator are autonomous in nature, they are permanently connected to the electrical system, run all the time and are completely self regulated ${ }^{1}$. Other devices such as washing machines, microwave ovens and televisions are fixed in place and constantly hooked up to the electricity supply via a wall socket either due to their size or because they are often used but only operate and therefore draw power when switched on by the consumer (either directly or via a timer setting) ${ }^{2}$.

In addition a whole host of devices ranging from small kitchen appliances through hair dryers and electric drills to mobile devices such as cell phones and media players are stored in cupboards or carried around and are only hooked up to the electrical system when they are in use or when they need to be charged up.

A person's use of particular devices will thus be highly varied and dependent on numerous factors ranging from the type of activities they do, i.e. do they cook, do

${ }^{1}$ Most refrigerators offer limited thermostat settings, which are either left at their factory setting or adjusted once in a blue moon.

${ }^{2}$ Some devices offering a standby position draw a small amount of electricity on a constant basis in order to maintain the standby position. 
they do laundry, etc., the frequency in which the use their cell phone and thus deplete the battery, whether they live alone or with other people, etc.

Lynch's [15] study of urban environments has shown that people develop detailed mental models of the urban landscape in which they live and that they conceptualize the environment based on the paths they traverse and the landmarks they pass or inhabit during the course of the day.

Do people develop a clear mental model of the electricity infrastructure in their home? Which of the devices with which they interact with stand out as the landmarks within these mental models? Is the electrical infrastructure as invisible as we tend to think or does it factor in people's conception of electricity in their homes?

\section{RQ3 - Which devices people think consume the most electricity?}

Not all devices are created equal, when it comes to consuming electricity, some are big in size but miserly, while others are small and nimble yet ravenous. Various factors come into play in determining the amount of electricity consumed by a particular device, the type of operation performed by the device, the length of use and the age are but of few of the factors involved. A proper estimation of the electricity consumed by a given device requires a clear understanding of the factor involved, an understanding that many residential householders may not have.

In their study of how Parisians conceive of their city Milgram and Jodolet [20] found that when people lack personal experience of a given part of a city they will readily use knowledge gained elsewhere or gleaned from the media to create a substitute image that is based as much on fiction as it is on fact.

Studies of people using the London underground system [29] have shown that use of the underground and in particular the development of a mental model of the underground based on a diagram of the system has significantly influenced the way in which they conceptualize the physical structure of the city. At times this misconception led to a huge over or under estimation of distances, severely impacting their navigation and decision-making.

Could the same factors be at play in the home environment with regards to the consumption of electricity? Is the understanding of people based on fact or is it fuelled by misconception?

\section{Methodology}

To conduct the study we opted for a phenomenological approach inspired by the work of Lynch [15]. Lynch wanted to uncover people's perceptions of the urban environments in which they were living. As part of the interviews he conducted with people he asked them to draw him an "image of the city". The resultant images often naïve portrayals of specific elements and segments of the urban landscape reflected the daily lives of particular individuals. However when taken as a whole and compared to one another the images showed certain commonalities highlighting certain landmarks and marking a common set of boundaries.

As of late a similar methodology was used by Poole, et al [24] in the context of home computer networks, by Yan [30] in understanding how children conceptualize the Internet and by Friedman et al [10] in understanding web security. 
As this is our first foray into this domain we decided to first launch a pilot investigation as a means of exploring the lay of the land and establishing the parameters on which further explorations will be based.

The study consisted of a short interview, intended to last for 15-45 minutes in which respondents were asked to draw 3 drawings and after the completion of each drawing describe the objects drawn and the reasons for drawing these objects. Participants were assured that no drawing skills are required and moderators were asked to keep the drawing time to less than a minute per drawing to minimize the potential for contemplation as much as possible as we wanted people to draw what first came to their mind.

At the end of the interview respondents were asked to provide basic demographic information such as age, gender, profession, however no identifying or contact information was collected and thus no follow up interviews were intended nor conducted with the participants.

The three drawings participants were asked to draw corresponded to the research questions posed in the study. For the first drawing respondents were posed with the question "draw me electricity" in an attempt to solicit the first image that came to their mind when they thought about electricity and thus their basic conception of electricity.

For the second drawing respondents were asked to draw all of the electrical elements in their home and for the third drawing they were asked to draw a pictorial representation of the 5 devices they thought consumed the highest amount of electricity.

No video or audio recordings were conducted during the interviews. Following the interviews the objects drawn in each of the drawings were coded and tabulated and summaries created of the types of objects appearing in the drawings.

\section{The Drawings}

Due to the exploratory nature of the investigation we did not seek to gather a statistically representative sample of the population nor did we concentrate on any particular segment of the population. We simply strove to attract a broad selection of participants from as wide a range of ages as possible in order to provide us with an initial glimpse into the subject domain.

Over a period of 4 weeks a group of 9 undergraduate students who were given training in the method of inquiry canvassed people in and around the city of Funchal, on the island of Madeira, for a brief interview about their perceptions of electricity. Participants were told we were conducting a study on sustainability and were not offered or given any remuneration for their participation.

In all the team interviewed a total of 454 respondents between the ages of 8 to 77 $($ Mean $=26.55, \mathrm{SD}=10.89)$, of which $50.4 \%(\mathrm{n}=229)$ were male and $49.5 \%(\mathrm{n}=225)$ were female.

Due to the predominance of young individuals, most of whom were students or young professionals in the sample, no attempt was made to analyze the results with regards to age or profession. The following is a preliminary analysis of the results. 


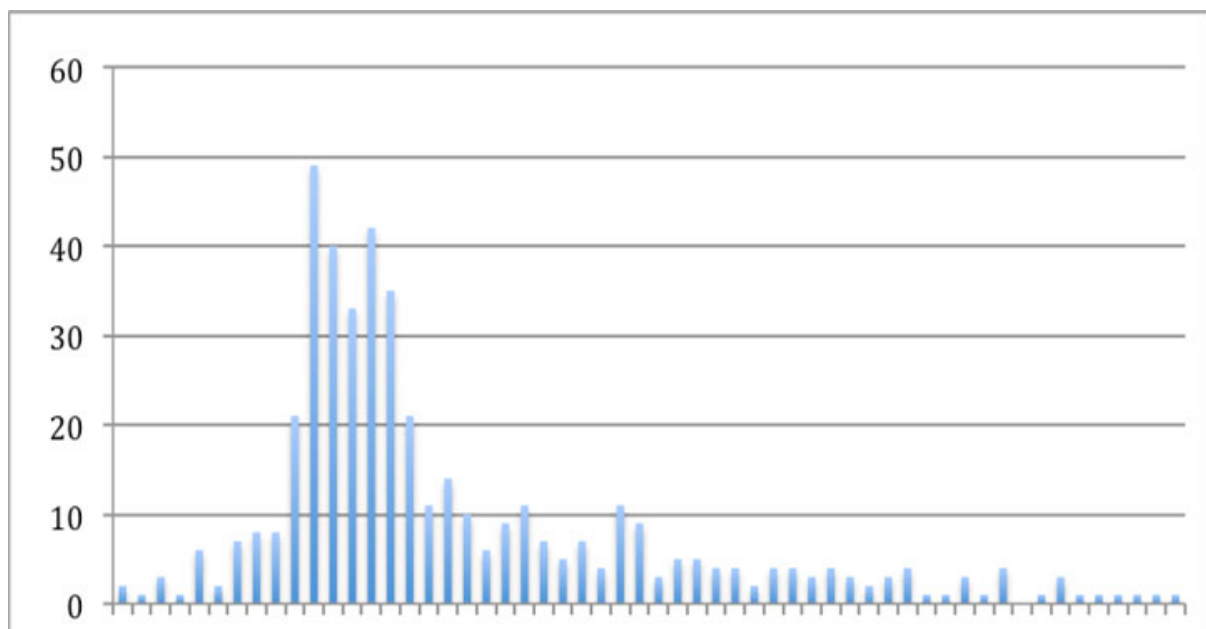

8101315171921232527293133353739414345474951535557596475

Fig. 1. Age breakdown of the respondents

\subsection{Drawing 1 - Draw Me Electricity}

In the first drawing participants were asked to draw the first thing that came to their mind when they thought of electricity. However in some cases the participants got carried away and drew several elements and the moderators caught in the heat of the moment failed to mark which of the elements was the first one to be drawn.

In order to maintain consistency when comparing the drawings, drawings containing more than one element were removed from the sample leaving a total of 400 drawings. The age and gender distribution within this sub-set remained largely unchanged. The age of the respondents ranged from 8 to 77 with a mean age of $26.19(\mathrm{SD}=10.76)$ of which $50.5 \%(\mathrm{n}=202)$ were females and $49.5 \%(\mathrm{n}=198)$ males.

The most commonly drawn object was a light bulb with $39.5 \%(n=158)$ of all drawings. An additional $6 \%(n=24)$ of participants drew various light fixtures making light the most common representation of electricity with $45.5 \% \quad(n=182)$ of all drawings. There was a marked difference between the genders here with $63.7 \%$ $(n=116)$ of the drawings drawn by females and $36.2 \%(n=66)$ being drawn by males.

When asked why they drew a light bulb or a light fixture all of the participants irrespective of gender remarked that electric lights are the most prevalent manifestation of electricity. Statements like "we are surrounded by light", "electric lights are everywhere", "light is the first thing I see" and "turning on the lights is the first thing I do" were repeated over and over again.

The second most common object drawn was Lightning with $19.25 \%(n=77)$ of the drawings. The majority drew simple representations of lightning bolts although a few drew more elaborate affairs portraying a thunderstorm complete with clouds and rain. When queried about the reasoning behind the drawing a large number said that although their initial thought was of a thunderstorm, the lightning bolt had a double meaning as it is often used as a warning sign on electrical installations. This set of drawings also displayed a marked difference between the sexes but in a reverse order with $77 \%(n=59)$ being drawn by males and $23 \%(n=18)$ by females. 

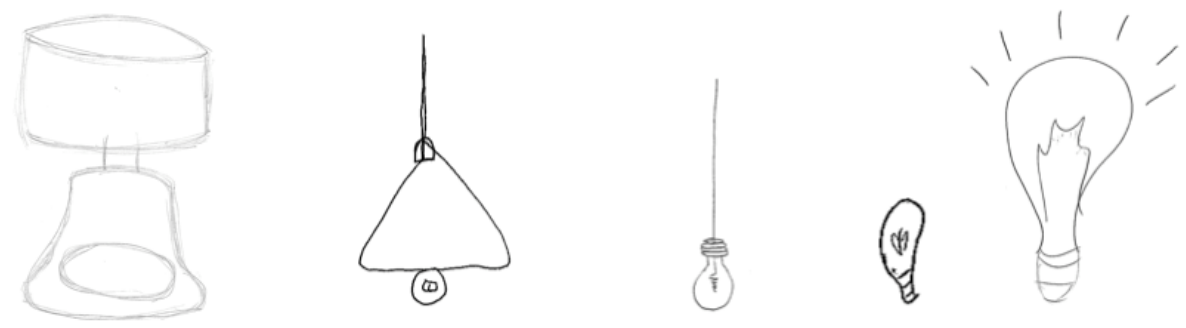

Fig. 2. A representative sample of the light bulbs and light fixtures drawn by the respondents
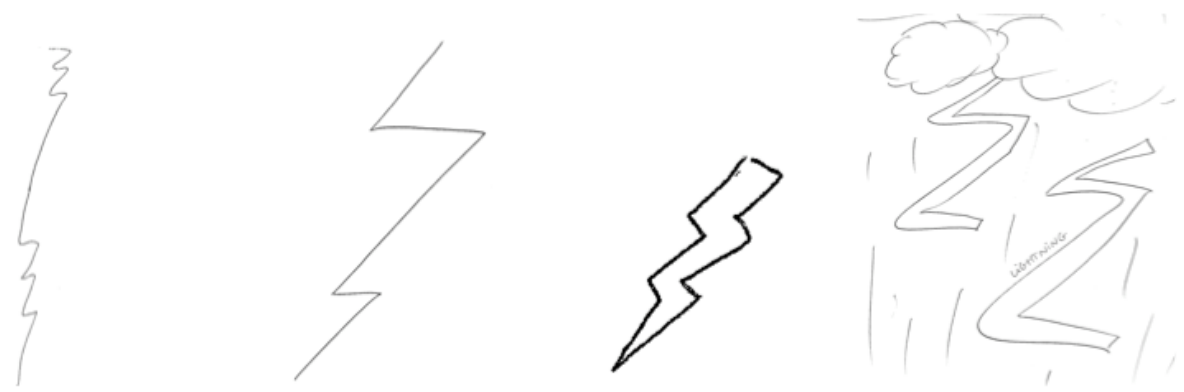

Fig. 3. A representative sample of the lightning bolts drawn by the respondents
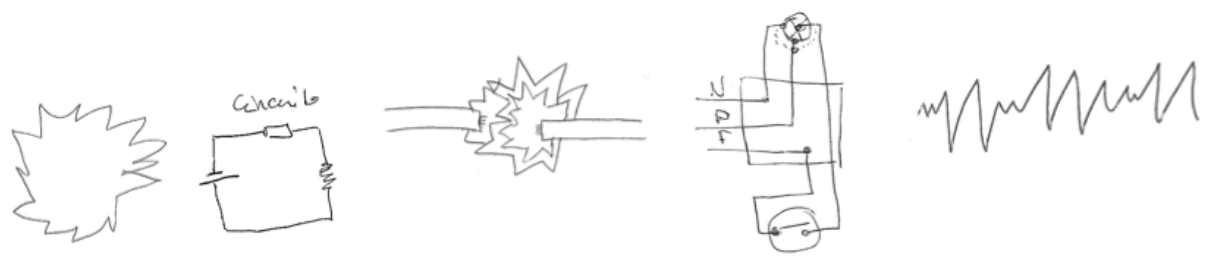

Fig. 4. A representative sample of abstract and diagrammatic representations of an electric current drawn by the respondents

In third place with $8.5 \%(n=34)$ were drawings of an electrical current drawn in either a purely abstract from $(n=20)$ or in a diagrammatic format showing an electrical circuit $(n=14)$. Of these $70.6 \%(n=24)$ were drawn by males and $29.4 \%(n=10)$ were drawn by females. The drawings created by the male respondents were equally divided between the abstract and diagrammatic formats while those drawn by female respondents were mainly abstract $(n=8)$

Electrical infrastructure elements such as electricity poles, cables and sockets were next in line with $7.5 \%(n=30)$ of participants divided equally between males and females drawing an electricity pole and $5 \%(n=20)$ drawing indoor power cables and plugs. Only $2 \%(n=4)$ of participants drew a wall socket and $0.75 \%(n=3)$ drew a light switch. 

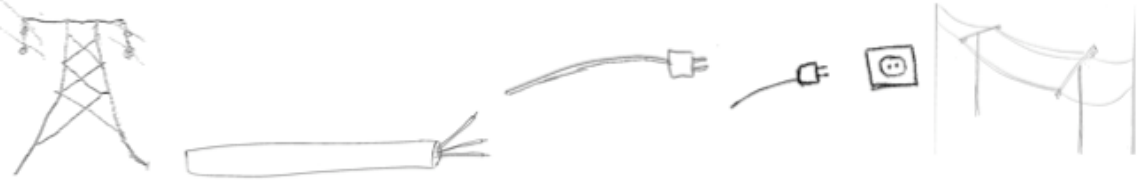

Fig. 5. A representative sample of the electricity infrastructure elements drawn by the respondents

The remaining drawings $(n=33)$ representing $8.25 \%$ of the total reflected a variety of notions from the concrete to the abstract. Two respondents drew a person with spiked hair and another drew a person being shocked while touching a surface as a representation of static electricity. Three respondents drew the symbol of the Euro as a representation of the cost of electricity. Two additional respondents drew batteries while another pair drew a representation of the flow of electrons in a wire as a representation of the essence of electricity. Moving towards the purely abstract one person drew a butterfly because it represents energy and colour and another drew a nightscape as "it is in the night when electricity is most needed"
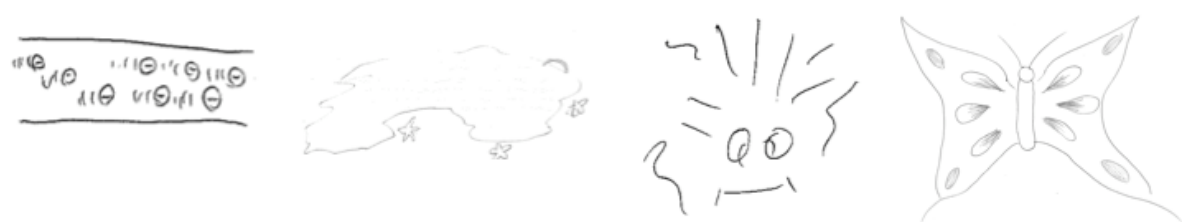

Fig. 6. Some of the more abstract representations drawn by the respondents, pictured from left to right, the flow of electrons thru a wire, a pictorial representation of the night, a person with statically charged spiked hair, and a butterfly drawn to represent energy and colour.

It is interesting to note that not a single respondent drew an image of a power station (with or without smoke stacks) although 3 of the respondents drew windmills and indicated their use as sustainable energy source, 3 others drew an image of the sun and indicated its potential as an alternative energy source and one respondent drew a representation of a hydro electric dam.

\subsection{Drawing 2 - Electricity in the Home}

In this drawing respondents were asked to draw electricity in their home. We sought to see the way in which people perceive and conceptualize electricity within their homes and whether the hidden and embedded infrastructure elements such as the electricity wires that snake through the walls as well as the sockets and switches that slightly protrude from the walls would be reflected in these perceptions. We suspected that infrastructure elements would by and large be hidden and that devices people use on a frequent basis would figure prominently in their perceptions.

Figure 7 provides an overview of the type of drawings created by the respondents. The vast majority of respondents $(79.42 \%, n=359)$ opted to simply draw various devices and elements on the page with no specific relationship between the objects 
drawn. A further $11.95 \%(n=54)$ drew floor plans of their homes and positioned the elements in their relative position in the home while another $8.63 \%(n=39)$ drew a stylized representation of their home and placed the entities within the home environment. Female respondents were more likely to draw floor plans $(n=38)$ or stylized representations $(n=28)$ than males who only drew 16 floor plans and 11 stylized representations. However the number of elements portrayed in each drawing was roughly the same with males drawing an average of $3.72(\mathrm{SD}=2.46)$ per drawing and females drawing an average of $3.83(\mathrm{SD}=2.64)$ elements per drawing.
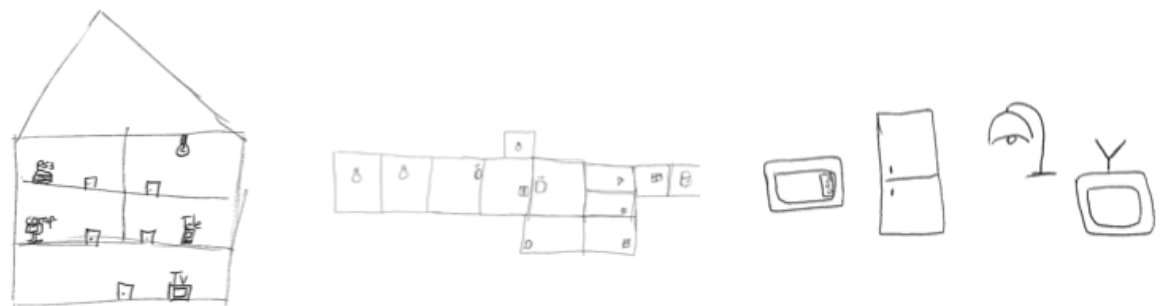

Fig. 7. A sample of the drawings created by the respondents for drawing 2

The drawings $(n=452)$ confirm our suspicion that infrastructure elements are by and large out of sight and out of mind, however they are not completely invisible with $24.11 \%(n=109)$ of the drawings containing at least one infrastructure element as illustrated in Table 1. Males appear to be more sensitive than females to infrastructure elements built into the walls such as wall sockets and wires but the their representations of the fuse box and the electricity meter appear to be more analogous.

Table 1. Electricity Infrastructure Elements in Drawing 2

\begin{tabular}{|l|c|c|c|c|}
\hline \multicolumn{1}{|c|}{ Element } & Female & Male & Total & Percentage \\
\hline Wall socket & 28 & 50 & 78 & 17.26 \\
\hline Fuse box & 12 & 14 & 26 & 5.75 \\
\hline Wire & 4 & 7 & 11 & 2.43 \\
\hline Power strip & 4 & 6 & 10 & 2.21 \\
\hline Electricity Meter & 3 & 4 & 7 & 1.55 \\
\hline
\end{tabular}

Electric lights figure prominently in the drawings with $46.20 \%(n=208)$ containing a representation of a lamp, a light bulb or a light switch. However lights also present a classification problem as some lights such as ceiling lights are built into the walls and are turned on from switches purposely built into the walls and thus may rightly perceived as part of the infrastructure of the house and others such as bed side lamps are stand alone devices which are turned on from a switch on the lamp and thus may be perceived as an independent device. Only $13.27 \%(n=60)$ contained a specific representation of a table or a floor lamp and they appeared more frequently in drawings created by females $(n=36)$ than by males $(n=24)$. $15.04 \%(n=68)$ of the drawings contained a drawing of a light bulb, with the bulbs appearing more 
frequently in drawings created by male respondents $(n=44)$ than those created by female respondents $(n=24)$. Ceiling lights drawn in either great detail or in purely abstract form appeared in $19.92 \%$ of the drawings $(n=90)$ with a higher preponderance in the drawings created by females $(n=55)$ to those created by males $(n=35)$. Light switches appeared in $5.31 \%(n=24)$ of the drawings with a fairly equal distribution between the genders with 13 drawn by males and 11 by females. In light of these data we are inclined to classify light as an infrastructure element.

The drawings also support our second hypothesis that devices people use on a frequent basis would feature prominently in their perception of electricity. Electric lights are a case in point however televisions appear to shine more brightly in the perceptions of the respondents with $52.21 \%(\mathrm{n}=236)$ of the drawings containing a representation of a television set and computers are not far behind appearing in $41.81 \%(n=189)$ of the drawings. Large domestic appliances loom large in the drawings appearing at least once in $54.65 \%(n=247)$ of the drawings. Refrigerators appear most frequently in the drawings followed by Microwave ovens and washing machines. Small appliances such toasters, juicers and irons feature in only $21.46 \%(n=97)$ of the drawings, most appear in only a few drawings and none have broken the $10 \%$ barrier.

An interesting anomaly but an understandable one given Madeira's mild weather is the almost total absence of heating and cooling devices in the drawings. In all only 1 air conditioner, 3 heaters, 4 fans and 4 dehumidifiers were drawn with the heaters and fans drawn mainly by males and the air conditioners and dehumidifiers mainly by females. A more interesting and less understandable anomaly is the low number of cell phones drawn with only $6.64 \%(n=30)$ containing a representation of a cell phone and the almost complete absence of iPods/MP3 players with only 3 iPods drawn despite the high prominence of these devices in everyday life and the high frequency in which they need to be charged. One explanation might be that these devices have become so ubiquitous that they, and the activities needed to support them have receded into the background.

Table 2 provides an overview of the devices that appear most frequently in the drawings created by male and female respondents. The percentages are computed per gender.

Table 2. Electrical Devices Featured Most Frequently in Drawing 2

\begin{tabular}{|c|l|c|c|l|c|c|}
\hline & \multicolumn{3}{|c|}{ Female } & \multicolumn{4}{c|}{ Male } & Count & $\%$ \\
\hline & Device & Count & $\%$ & Device & 116 & 50.66 \\
\hline 1 & Television & 120 & 53.81 & Television & 103 & 44.98 \\
\hline 2 & Computer & 86 & 38.57 & Computer & 77 & 33.62 \\
\hline 3 & Refrigerator & 85 & 38.12 & Refrigerator & 55 & 24.02 \\
\hline 4 & Microwave & 62 & 27.80 & Microwave & 35 & 15.28 \\
\hline 5 & $\begin{array}{l}\text { Washing } \\
\text { machine }\end{array}$ & 41 & 18.39 & Washing machine & & \\
\hline 6 & Toaster & 21 & 9.42 & Radio & 17 & 7.42 \\
\hline 7 & Hair dryer & 20 & 8.97 & Cell phone & 14 & 6.11 \\
\hline 8 & Radio & 16 & 7.17 & Iron & 14 & 6.11 \\
\hline 9 & Cell phone & 16 & 7.17 & Oven & 13 & 5.68 \\
\hline 10 & Iron & 15 & 6.73 & Stereo system & 11 & 4.80 \\
\hline
\end{tabular}




\subsection{Drawing 3 - Draw the Highest Consuming Devices}

In this drawing respondents were asked to draw representations of 5 electrical devices in their homes they thought consumed the highest amount of electricity.

Although an extensive range of appliances and devices was drawn ranging from Aquariums, air compressors, alarm clocks, curling irons and cement mixers through electric guitars, humidifiers and foot massagers to sewing machines, soldering irons and water coolers those that appeared most frequently were of a more mundane nature as listed in table 3. Unfortunately the order in which the devices were drawn was not recorded so we cannot say which device was drawn first, second and so forth and only report on the total occurrence of specific devices in the drawings.

The drawings and the comments made by the respondents reflect the notion that people do not have an accurate sense of the amount of electricity consumed by a particular device and tend to associate consumption level with the frequency and duration of use as well as with the size of the device.

Table 3. Top 10 Most Frequently Drawn Devices in Drawing 3

\begin{tabular}{|l|c|c|l|c|c|}
\hline \multicolumn{3}{|c|}{ Female } & \multicolumn{3}{c|}{ Male } \\
\hline Device & Count & Percentage & Device & Count & Percentage \\
\hline Television & 141 & 62.67 & Refrigerator & 154 & 67.25 \\
\hline Refrigerator & 139 & 61.78 & Television & 145 & 63.32 \\
\hline $\begin{array}{l}\text { Washing } \\
\text { machine }\end{array}$ & 131 & 58.22 & Computer & 127 & 55.46 \\
\hline Computer & 112 & 49.78 & $\begin{array}{l}\text { Washing } \\
\text { machine }\end{array}$ & 121 & 52.84 \\
\hline Microwave & 92 & 40.89 & Microwave & 102 & 44.54 \\
\hline Iron & 61 & 27.11 & Iron & 56 & 24.45 \\
\hline Deep freezer & 57 & 25.33 & Light & 55 & 24.02 \\
\hline Light & 48 & 21.33 & Deep freezer & 42 & 18.34 \\
\hline Water heater & 34 & 15.11 & Oven & 32 & 13.97 \\
\hline Tumble Dryer & 32 & 14.22 & Water heater & 28 & 12.23 \\
\hline
\end{tabular}
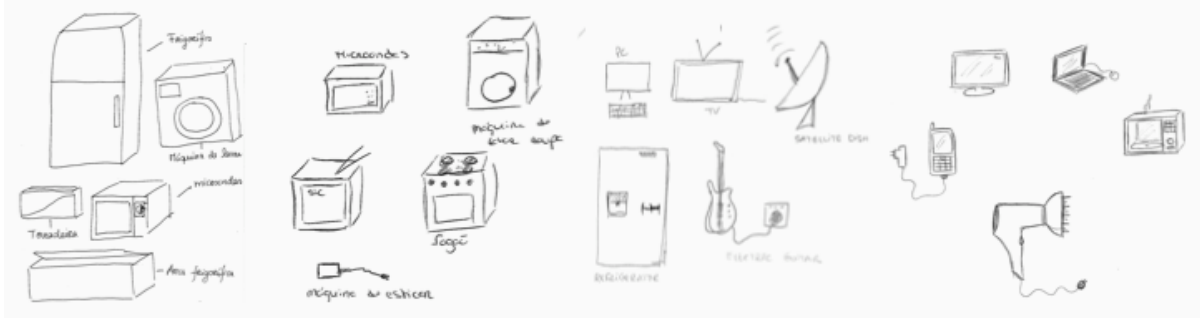

Fig. 8. A Sample of the drawings created by the respondents for drawing 3 
Most of the devices listed in Table 3 consume low to moderate levels of electricity but when queried about why they drew a particular device respondents constantly made references to size, duration and use, with statements like, "the television is on all the time so it must be consuming lots of electricity", "I have lots of lights in my house", "we have a big deep freezer", "the kids use the computer all the time".

In one extreme example a 23-year-old male drew a small aquarium, a fridge, a deep freezer, a television and a computer. When queried about the drawing he said the water pump and the light in the aquarium are on all the time, he watches a lot of television and spends a lot of time with the computer and the refrigerator and deep freezer are very big and for these reasons they each consume a lot of electricity.

A few respondents drew a person in addition to devices to highlight the high rate of consumption brought about by a particular individual. An example can be seen in the drawings of two respondents. The first, a 28-year-old male who in addition to a computer, refrigerator, iron and a television, drew his girlfriend, and noted that she never turns off the lights in his apartment. The second, a 25-year-old female, drew her grandmother in between a television (intended to represent the $4 \mathrm{TV}$ sets in her house), a computer, a cell phone (intended as a representation of the 5 cell phones in her house) and a microwave and complained that the old lady uses the washing machine and tumble dryer on a daily basis and thus consumes a lot of electricity.

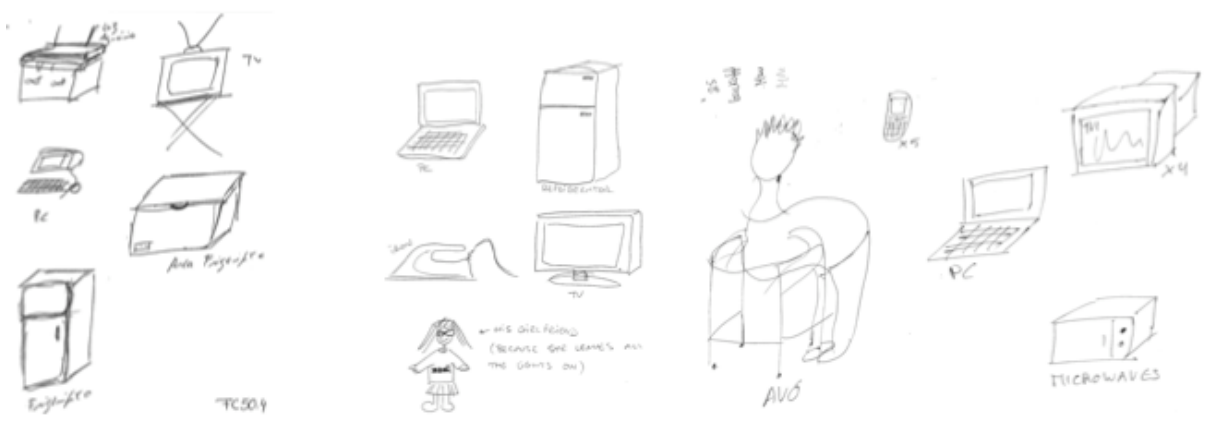

Fig. 9. A tale of an aquarium, a girlfriend and a grandmother

\subsection{Some Initial Conclusions}

Although the results of the study were drawn from the population of the city of Funchal and its outlying areas and therefore represent the perceptions of an urban population with a predominantly European background we believe that they provide a valuable insight into people's perceptions of electricity on which further study and reflection can be based.

The drawings confirm our suspicion that people lack a coherent mental model of electricity. The hidden and mediated nature of electricity means that people's perceptions of electricity are shaped by the devices that pervade their daily lives, and, as a result electric lights, computers, televisions and a host of domestic appliances dominate individual perceptions of electricity. Without visual cues to the amount of electricity consumed by each device people seem to rely on mental models and 
associations gleaned elsewhere. Thus, the size of the device, the duration of use and the frequency of use become proxies for rates of consumption. As a result people ascribe high consumption levels to the most miserly of devices, to the extent that even the lowly aquarium light may be perceived as an electricity guzzler simply because it is on all of the time.

An examination of the devices listed in Table 3 reveals only minor difference in the perceptions of males and females with with regards to which devices consume the highest amount of electricity. Thus although the males of the species may not do as many loads of laundry as the females, they both attribute the device with a high level of consumption. After all frequency and size are in the eyes of the beholder, regardless of whether the beholder actually uses the machine or beholds an image of someone else using the machine as illustrated in Figure 10.
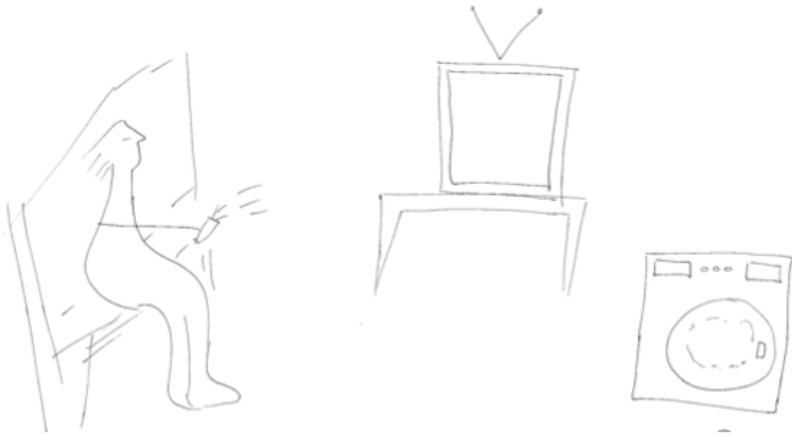

Fig. 10. Still life with husband, television and washing machine. A drawing of electricity in the home created by a 36 year old, female

\section{Discussion}

In Understanding Media, McLuhan [18] famously quipped, "The medium is the message". In the same volume he used electric light as an example stating, "The electric light is pure information. It is a medium without a message...". McLuhan wanted to stress a point, that the impact (message) of a technology (media) was not what the technology enabled, or even what one did with the technology but what were the social ramifications of the technology and the patterns of use that followed its adoption.

To paraphrase McLuhan's example the importance of the railway is not in the way it harnessed rails, wheels and steam power to move people and cargo, or in the specific trips individual people made but in the new types of urban forms and new forms of work and leisure activities that have emerged.

In this sense the light bulb is indeed a medium without a message unless the message is one of convenience and abundance. However we must ask ourselves whether the social ramifications of a technology convey the whole message or are they just one aspect of the story. 
A light bulb emits light, that is plain to see, but if we hold our hand next to it, we can sense that it also emits heat. The heat we can feel being emitted from the lamp and the emissions released by the power station that powers it are costs whose ramifications have largely been ignored until now.

Most current sustainability related efforts have been geared towards bringing electricity and the hidden costs associated with its consumption to the attention of consumers in an effort to elicit a more sustainable lifestyle. However as the drawings reveal we are not only facing a problem of visibility we are also facing a problem of legibility. By legibility we essentially mean the ease in which people interpret and understand a place, a technology or a piece of information. The challenge now is how to make the consumption of electricity not only more visible but also more legible. The issue of legibility raises a number of interesting questions.

1. How can we imbue electricity and its consumption with a meaning people can easily perceive and relate to?

2. How can we relate the consumption rate of individual devices in a way that would enable people to develop a mental model based on the properties of a device, i.e. does it provide light, heat, refrigeration, etc. as opposed to its size, duration or frequency of use?

3. How can we utilize the notions of size, frequency and duration in promoting more sustainable use and consumption patterns?

As noted above one of the difficulties with the consumption of electricity is its invisible nature. People tend to have difficulty conceptualizing invisible or purely abstract concepts such as electricity, preferring instead to rely on visible manifestations and physical properties such as the light emitted by a bulb or the size of a refrigerator.

One answer to the above questions would be to use light and the size of a device as elements in design. Gustafsson \& Gyllenswärd [12] successfully made manifest the flow of electricity through a cord by making the cord glow with light. Why not extend the metaphor and make the whole refrigerator glow with light. By contrasting the large size of the refrigerator with a low level of ambient light (since refrigerators are relatively low consumers of electricity) we will hopefully enable users of the refrigerator to make the correct relationship between size and consumption level. A whole house equipped with such appliances will enable the residents to map lout their electrical consumption and focus their conservation efforts on particular problem spots.

Further playing with the notions of size, duration and frequency of use which seem to dominate the perceptions of the study participants we can use Non Invasive Load Monitoring (NILM) devices to get a detailed record of the electrical consumption of various devices in the house and then display graphical representations of the consumption levels of these devices coupled with pithy quirky messages. For example, a television may display the following message upon stating up "I maybe a 42 " television screen but I only consume as much electricity as the toaster you used this morning". 


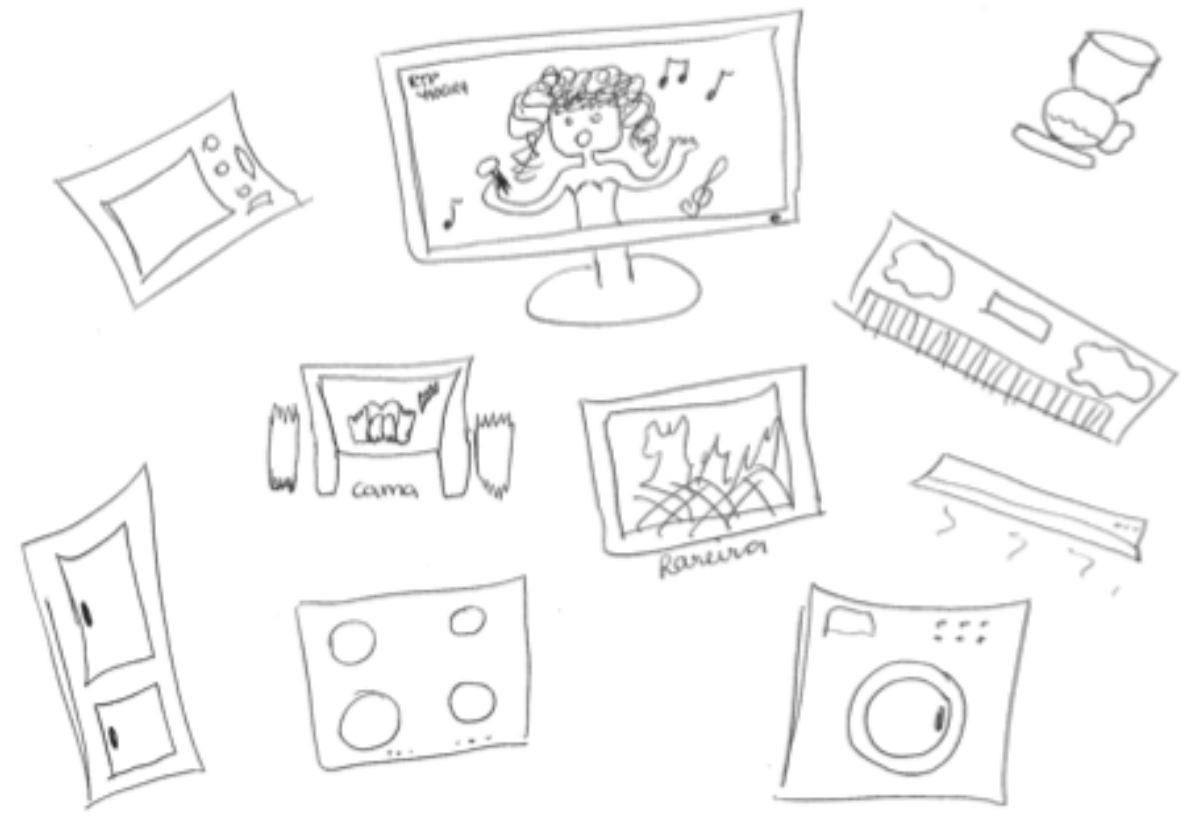

Fig. 11. The consumption and production of electricity in the home as portrayed by a 30 year old female respondent. Electricity is consumed by a host of domestic appliances; the consumption is then offset by electricity generated as a result of amorous activities in the marital bed.

\section{Conclusion}

In The Image of The City, the work that provided the initial inspiration for this study, Lynch [15] strove to discover how people understood the structure of cities, what were their perceptions of specific areas of the city, how did they navigate through the space and how would they define and portray its properties to others. Lynch's objective was to understand the legibility and imageability of urban places, properties that would not only allow the inhabitants to easily navigate through the city but that would also foster a local identity and pride of place and that would allow urban planners and developers to create urban environments that are liveable as well as habitable.

In this work we strove to follow in Lynch's footsteps by trying to uncover people's perceptions of electricity in order to devise methods that would make electricity more legible and imageable (to use Lynch's terms) and thus support a more sustainable use of electricity, one that is based on understanding of the benefits and consequences of the consumption of energy as opposed to one based on indifference, ignorance and guilt.

Although the study was conducted within the confines of a small island with a fairly homogenous population we believe the work provides valuable insights into how people perceive electricity and how perceive the consumption levels of individual devices and thus to be of use both to HCI researchers looking to develop sustainable technologies and technologies intended to support sustainability and researchers in other fields engaged in projects related to electricity and sustainability. 
We intend to pursue this work further by conducting additional studies in which we will seek both to validate the findings by surveying a more diverse population base on which we could conduct rigorous statistics test and to expand the scope of the work by looking at additional aspects such as the electricity grid and the energy sources used to power it.

We would like to end this paper with a final image. An image we believe portrays both the rich insights on electricity provided by this study, insights we have only begun to explore and thus only cursorily presented in this paper and the power of drawing as a tool for eliciting rich information on recalcitrant topics from reserved as well as responsive respondents.

Acknowledgements. Support for this research was provided by the Fundação para a Ciência e a Tecnologia (Portuguese Foundation for Science and Technology) through the Carnegie Mellon Portugal Program as part of SINAIS - Sustainable Interaction with social Networks, context Awareness and Innovative Services (CMUPT/HuMach/0004/2008). Additional funding was provided by CITMA - Centro de Ciência e Tecnologia da Madeira (The Madeira Center for Science and Technology). We would also like to thank the students who helped conduct the fieldwork for this study; Angela Ferreira, Catarina Dias, Elvio Pita, Francisco Andrade, Francisco Capelo, Maurilia Nobrega, Nicolene Baeta, Yesica Reynolds, and Wilmer Goncalves; all of the participants who contributed their time, patience and drawing skills to this effort; and the anonymous reviewers who provided helpful feedback on an earlier draft of this paper.

\section{References}

1. Attari, S.Z., DeKay, M.L., Davidson, C.I., de Bruin, W.B.: Public perceptions of energy consumption and saving. In: Proceedings of the National Academy of Sciences of the United States of America (2010); PNAS published ahead of print August 16, 2010, Retrieved from:

http: / /www.pnas.org/content/early/2010/08/06/1001509107.

full.pdf + html

2. Bostrom, A., Morgan, M.G., Fischhoff, B., Read, D.: What do people know about global climate change? 1. Mental models. Risk Analysis 14(6), 959-970 (1994)

3. Chetty, M., Banks, R., Harper, R., Regan, T., Sellen, A., Gkantsidis, C., Karagiannis, T., et al.: Who's Hogging The Bandwidth?: The Consequences Of Revealing The Invisible In The Home. Technology, 659-668 (2010)

4. Chetty, M., Brush, A.J.B., Meyers, B.R., Johns, P.: It's not easy being green: understanding home computer power management. In: Proceedings of the 27th International Conference on Human Factors in Computing Systems (CHI 2009), pp. 1033-1042 (2009)

5. Chetty, M., Tran, D., Grinter, R.E.: Getting to green: understanding resource consumption in the home. In: Proceedings of the 10th International Conference on Ubiquitous Computing (UbiComp 2008), pp. 242-251 (2008)

6. Darby, S.: The Effectiveness of Feedback on Energy Consumption. A Review for DEFRA of the Literature on Metering Billing and direct Displays. Oxford University Environmental Change Institute (2006), Retrieved from:

http: / / www.vaasaett.com:81/xmlui/handle/123456789/133

7. Dillahunt, T., Mankoff, J., Paulos, E., Fussell, S.: It's not all about "Green": energy use in low-income communities. In: Proceedings of the 11th International Conference on Ubiquitous Computing (Ubicomp 2009), pp. 255-264 (2009)

8. Dunlap, R.E.: Lay Perceptions of Global Risk: Public Views of Global Warming in CrossNational Context. International Sociology 13, 473-498 (1998) 
9. Foster, D., Lawson, S., Blythe, M., Cairns, P.: Wattsup?: Motivating reductions in domestic energy consumption using social networks. In: Procedings of Nordi CHI 2010 (2010)

10. Friedman, B., Hurley, D., Howe, D.C., Felten, E., Nissenbaum, H.: Users' Conceptions of Web Security: A Comparative Study. In: CHI 2002 Extended Abstracts. ACM Press, New York (2002)

11. Froehlich, J., Findlater, L., Landay, J.: The design of eco-feedback technology. In: Proceedings of the 28th International Conference on Human Factors in Computing Systems, CHI 2010 (1999)

12. Gustafsson, A., Gyllenswärd, M.: The power- aware cord: energy awareness through ambient information display. In: Ext. Abs. CHI 2005, pp. 1423-1426. ACM Press, New York (2005)

13. He, H.A., Greenberg, S.: Motivating Sustainable Energy Consumption in the Home. Psychologist, 1-5 (2008)

14. Furby, L., Slovic, P., Fischhoff, B., Gregory, R.: Public Perceptions of Electric Power Transmission Lines. Journal of Environmental Psychology 8, 19-43 (1988)

15. Lynch, K.: The Image of the City. MIT Press, Cambridge (1960)

16. Mankoff, J., Matthews, D., Fussell, S.R., Johnson, M.: Leveraging Social Networks to Motivate Individuals to Reduce their Ecological Footprints. In: Proc. HICSS 2007 (2007)

17. Martin, N.: Habit: The 95\% of Behavior Marketers Ignore. FT Press, Upper Saddle River (2008)

18. McLuhan, M.: Understanding Media: The Extensions of Man. MIT Press, Cambridge (1994)

19. Mehlwana, A.M.: The anthropology of fuels: situational analysis and energy use in urban low-income townships of South Africa. Energy for Sustainable Development 3(5), 5-15 (1997); International Energy Initiative, Inc., Retrieved from

http://linkinghub.elsevier.com/retrieve/pii/S0973082608602082

20. Milgram, S., Jodelet, D.: Psychological maps of Paris. In: Proshan, H., Ittelson, W., Rivlin, L. (eds.) Environmental Psychology, 2nd edn., pp. 104-124. Holt, Rinehart \& Winston, New York (1976)

21. Pierce, J., Odom, W., Blevis, E.: Energy aware dwelling: a critical survey of interaction design for eco-visualizations. In: Proceedings of the 20th Australasian Conference on Computer Human Interaction - Designing for Habitus and Habitat, pp. 1-8 (2008)

22. Pierce, J., Paulos, E.: Materializing energy in everyday life. In: Proceedings of CHI 2010 (2010)

23. Pierce, J., Schiano, D.J., Paulos, E.: Home, Habits, and Energy: Examining Domestic Interactions and Energy Consumption. Human Factors, 1985-1994 (2010)

24. Poole, E.S., Chetty, M., Grinter, R.E., Edwards, W.K.: More than meets the eye: transforming the user experience of home network management. Designing Interactive Systems, 455-464 (2008)

25. Read, D., Bostrom, A., Morgan, M.G., Fischhoff, B., Smuts, T.: What do people know about global climate change? 2: Survey Studies of Educated Laypeople. Risk Analysis 14(6), 971-982 (1994)

26. Rittel, H., Webber, M.: Dilemmas in a General Theory of Planning. Policy Sciences 4, 155-169 (1973)

27. Sengers, P., Boehner, K., David, S., Kaye, J.: Reflective design. In: Proc. of Critical Computing 2005, pp. 49-58. ACM Press, New York (2005)

28. Strengers, Y.: Smart metering demand management programs: challenging the comfort and cleanliness habitus of households. In: Proceedings of the 20th Australasian Conference on Computer Human Interaction, OZCHI 2008, pp. 9-16 (2008)

29. Vertesi, J.: Mind the Gap: The "Tube Map" as London's User Interface. In: Engaging the City Workshop Paper, CHI 2005 (2005)

30. Yan, Z.: What Influences Children' s and Adolescents' Understanding of the Complexity of the Internet? Developmental Psychology 42(3), 418-428 (2006) 